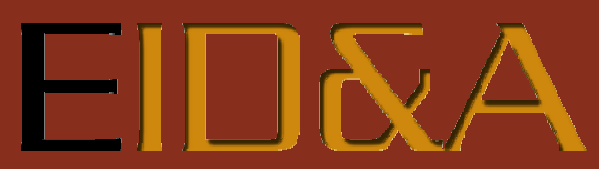

Revista Eletrônica de Estudos Integrados em Discurso e Argumentação

\title{
O FUNCIONAMENTO ARGUMENTATIVO EM TORNO DA DESIGNAÇÃO “REFUGIADOS” NO DISCURSO UNIVERSITÁRIO BRASILEIRO
}

\author{
Marluza da Rosaii
}

\begin{abstract}
Resumo: Este trabalho objetiva analisar e compreender as relações de poder-saber na esfera discursiva universitária, de modo a explorar os efeitos de sentido resultantes da forma como são designadas as pessoas em situação de refúgio em documentos que regem o processo seletivo para ingresso de refugiados no ensino superior brasileiro. Tomar a questão pelo viés da argumentação e do discurso permite que se estabeleçam profícuos debates em torno de uma visada analítica voltada para o âmbito acadêmico enquanto cenário político não só de divisão de sentidos (ORLANDI, 1998), mas também de relação entre forças heterogêneas que implicam a possibilidade do dissenso (RANCIÈRE, 1998, 2000). Com base nessa perspectiva teórico-metodológica, a análise desenvolvida explora o funcionamento da designação e aponta para sua inscrição na materialidade discursiva, por meio de deslocamentos nas formas de designar, ao longo do tempo e nos diferentes textos.
\end{abstract}

Palavras-chave: Refugiados. Universidade. Discurso. Argumentação.

\begin{abstract}
This paper aims to analyze and understand the relations of powerknowledge in the university discursive sphere, to explore effects of meaning resulting from the way refugees are defined in documents that govern Brazilian higher education admissions process for refugee students. Examining this question through argumentation and discourse allows us to establish fruitful debates around an analytical perspective aimed at the academic field as a political scenario not only of division of meanings (ORLANDI, 1998), but also of relation between heterogeneous forces which imply the possibility of dissent (RANCIÈRE, 1998, 2000). Based on this theoretical-methodological perspective, the developed analysis explores the functioning of the designation and points to its inscription in the discursive materiality, through displacements in the forms of designating through time and in different texts.
\end{abstract}

Keywords: Refugees. University. Discourse. Argumentation.

\footnotetext{
'À memória do colega Prof. Dr. Wesley Grijó.

ii Professora Doutora da Universidade Federal de Santa Maria, câmpus Frederico Westphalen (UFSM/FW), Brasil. E-mail: marluza.rosa@gmail.com.
} 
EID\&A - Revista Eletrônica de Estudos Integrados em Discurso e Argumentação, Ilhéus, n. 15, jan./jun.2018.

\section{Introdução}

A segunda década do século XXI tem sido marcada por movimentos migratórios e noticiada, nos diferentes meios de comunicação, como a pior crise de migração desde a Segunda Guerra. Discussões acerca dessa problemática em diferentes países são, portanto, recorrentes nos dias de hoje. Porém, a respeito do ingresso deste grupo minoritário, migrantes e refugiados, em instituições de ensino, mais precisamente, na Universidade brasileira, ainda há poucas pesquisas desenvolvidas.

Conforme dados divulgados nos últimos anos, o Brasil abriga quase 9 mil refugiados de 79 nacionalidades ${ }^{1}$. Dentre estes, há uma grande porcentagem de jovens adultos em idade de iniciar ou cursar o ensino superior. Consequentemente, desde o fim da década de 1990, mas visivelmente nos anos mais recentes, dada a crise humanitária decorrente de conflitos armados em países do Oriente Médio, nossas IES têm se voltado cada vez mais à proposta de possibilitar o "ingresso facilitado" de pessoas em situação de refúgio, de acordo com a Lei $n^{\circ}$. 9.474/1997, a qual apregoa que:

[...] o reconhecimento de certificados e diplomas, os requisitos para a obtenção da condição de residente e o ingresso em instituições acadêmicas de todos os níveis deverão ser facilitados, levando-se em consideração a situação desfavorável vivenciada pelos refugiados (grifos nossos) ${ }^{2}$.

Em diálogo com setores responsáveis por essa acolhida em algumas das instituições que pesquisamos, fomos informados que o número de refugiados ingressantes ainda é pouco significativo, o que aponta para uma discrepância: ao mesmo tempo em que há um aumento no contingente de pessoas amparadas pelo Estatuto do Refugiado no Brasil, seu acesso ao ensino superior permanece baixo e, por vezes, inexistente. Por outro lado, esse público ocupa cada vez mais os empregos considerados precários, insalubres e de pouca legitimidade social. Assim, mesmo que o país disponha de universidades públicas com programas específicos de ingresso direcionados aos refugiados, sua formação educacional superior nem sempre é possível, fazendo com que se privem não só do acesso a um ensino público de qualidade e a uma formação profissional que lhes permita reconstruir suas vidas, mas também de visibilidade e representatividade social e cultural.

\footnotetext{
Disponível em: http://www.brasil.gov.br/cidadania-e-justica/2016/05/brasil-abriga-8-863refugiados-de-79-nacionalidades.

${ }^{2}$ O texto da lei pode ser acessado em: http://www.planalto.gov.br/ccivil_03/leis/L9474.htm.
} 
EID\&A - Revista Eletrônica de Estudos Integrados em Discurso e Argumentação, llhéus, n. 15, jan./jun.2018.

Nesse cenário, este trabalho toma como objeto de análise documentos, em formato de editais, portarias e resoluções, divulgados online nas páginas institucionais de sete ${ }^{3}$ universidades públicas brasileiras que possuem processo seletivo para ingresso de refugiados em seu corpo discente. 0 estudo se insere no âmbito do projeto de pesquisa que coordeno na Universidade Federal de Santa Maria, intitulado Discurso, poder e políticas da (in)visibilidade. Discutiremos, neste artigo, as diferentes formas de designar os refugiados, presentes nesses documentos, partindo do pressuposto de que nomear/designar consiste em um gesto político que produz sentidos (ORLANDI, 1998; RANCIÈRE, 2000). O estudo busca investigar, nos textos analisados, como se constroem categorias que englobam ou excluem, no discurso e no âmbito institucional acadêmico, o estrangeiro que busca refúgio. Concordamos com Amossy (2011, p. 133), quando a autora salienta que "é na espessura da língua que se forma e se transmite a argumentação". Uma vez que a língua é a base dos processos discursivos, é possível compreender, consequentemente, a argumentação como um mecanismo discursivo que possibilita determinadas orientações de sentido e não outras, o que justifica um olhar problematizador para seu funcionamento, bem como para o conjunto de práticas e técnicas que a ela se atrelam.

Tomar a questão pelo viés da Análise de Discurso permite que se estabeleçam debates em torno de uma visada analítica voltada para o âmbito acadêmico enquanto cenário político não só de divisão de sentidos (ORLANDI, 1998), mas também de relação entre forças heterogêneas que implicam a possibilidade do dissenso (RANCIÈRE, 1998, 2000). Por atravessar a esfera pública e social, caracterizada por jogos de força (FOUCAULT, 2009), cabe ressaltar que a problemática interessa ao conjunto de estudos que se voltam ao processo de produção de (in)visibilidade, a qual consiste em "um revelador essencial da estruturação das sociedades contemporâneas, implicando desafios específicos e tendo consequências na formação das lutas sociais e políticas" (VOIROL, 2005, p. 92) ${ }^{4}$.

\footnotetext{
${ }^{3}$ Quais sejam: Universidade Federal de São Carlos (UFSCar), Universidade Federal de Minas Gerais (UFMG), Universidade Federal de Juiz de Fora (UFJF), Universidade de Brasília (UnB), Universidade Federal do Rio Grande do Sul (UFRGS), Universidade Federal do Paraná (UFPR) e, mais recentemente, Universidade Federal de Santa Maria (UFSM).

${ }^{4}$ Tradução nossa para: "un révélateur essentiel de la structuration des sociétés contemporaines inpliquant des enjeux spécifiques et ayant des conséquences sur la formation des luttes sociales et politiques".
} 
EID\&A - Revista Eletrônica de Estudos Integrados em Discurso e Argumentação, llhéus, n. 15, jan./jun.2018.

Para desenvolver a proposta aqui anunciada, apresentaremos, inicialmente, uma leitura a respeito da articulação entre designação e argumentação no plano do discurso. Em seguida, discutiremos alguns excertos dos documentos, nos quais é possível identificar uma oscilação nos modos de designar e de significar, linguística e discursivamente, os refugiados. Tal oscilação sugere tanto uma tentativa de controle dos sentidos e de precisão dos termos utilizados, quanto uma categorização e uma inserção das designações e dos migrantes em um dispositivo jurídico e administrativo.

\section{Designação, argumentação e discurso}

A designação tem se configurado como um local de interesse para a Análise de Discurso por pressupor uma relação entre uma materialidade linguística e uma materialidade histórica, constituindo, conforme nos ensina Pêcheux (1990), uma materialidade discursiva. Na esteira do autor, Nunes (2006, p. 152) a compreende como um "objeto linguístico afetado pelo discurso", o que implica que a designação não é uma classificação objetiva, uma vez que é atravessada por uma memória discursiva, na qual se entrelaçam outras formas de designar no fio do tempo e dos dizeres.

Embora heterogênea, porque marcada pelos discursos, a designação funciona de modo a construir a homogeneidade e a unicidade do sujeito/objeto designado. Nesse sentido, produz um efeito de evidência e de amálgama entre palavra e objeto, conforme Guimarães, para quem a designação "constrói continuamente o objeto designado sob a aparência de ser uma palavra para um objeto desde sempre" (GUIMARÃES, 2003, p. 58, grifo nosso). Ora, essa estabilização dos sentidos não se dá senão na linearidade do dizer e, mesmo nesse âmbito, pouco se sustenta, pois essa linearidade se produz a partir da memória discursiva, na sua dimensão de real (da história), que esburaca o estável, deixando entrever uma dispersão de outros discursos que lhe são constitutivos. Quando se trata das designações que categorizam e distinguem migrantes e refugiados, por exemplo, conforme Jardim (2016, p. 255), faz-se necessário considerar que estas “interatuam em situações históricas precisas. Não poderíamos percebê-las como um recurso atemporal e desde sempre disponível a pessoas que perfazem um êxodo forçado".

É na relação com a memória que também pode ser pensado o funcionamento da argumentação na perspectiva discursiva, pois, para Amossy 
EID\&A - Revista Eletrônica de Estudos Integrados em Discurso e Argumentação, llhéus, n. 15, jan./jun.2018.

(2011, p. 133-139), a argumentação está inscrita tanto no emprego de elementos lexicais, nos deslizamentos semânticos, quanto no interdiscurso. Nesse sentido, dada a heterogeneidade constitutiva, a argumentação é vista pela autora como inerente ao âmbito do discurso. Dessa forma, torna-se possível observar, no funcionamento da designação, a intervenção do plano interdiscursivo no intradiscursivo, ou seja, a ressignificação de uma memória na linearidade do discurso. Assim sendo, o domínio ao qual a designação se associa concerne tanto ao fio do discurso, visto que se relaciona ao que a contiguidade do dizer veicula, quanto à verticalidade do interdiscurso (memória discursiva), onde se enlaça com outras formas de designar, respondendo-as, contrapondo-se a elas ou delas diferindo.

Nas designações que observaremos, considerando o plano intradiscursivo, ao substantivo "refugiado"5 ou "migrante", são acrescidos termos que se encarregam de reformular o nome. No entanto, o deslizamento de sentidos vai se produzir não só na formulação linguística, mas também em uma trama histórica de dizeres. Sendo assim, tratamos a designação como constitutiva do discurso e de natureza argumentativa, uma vez que, além de figurar e de significar no plano linear do dizer, evoca sentidos não ditos, que fazem parte de uma rede de outros sentidos.

Como sinalizado ainda na introdução, as designações analisadas possuem caráter oscilante e se estruturam - com o auxílio de adjuntos e orações restritivas e explicativas, que reescrevem e/ou ressignificam os elementos lexicais centrais -, como tentativas de precisar os sentidos, de explicar e explicitar quem está ou pode vir a ser inserido na categoria "refugiado". Como as designações não são unívocas e seus sentidos são apenas provisoriamente estáveis, essa categorização relaciona-se a outras, delas se distingue, "reage à palavra do outro, quer seja para retomá-la, modificá-la ou refutá-la” (AMOSSY, 2011, p. 133).

2. A designação "refugiado" e seus entornos, um funcionamento argumentativo

Os recortes apresentados foram organizados cronologicamente em razão do ano de publicação dos documentos - editais, portarias e resoluções o que nos permite visualizar o deslocamento nas formas de designar. Nos

\footnotetext{
${ }^{5}$ O termo "refugiado" também é empregado como adjetivo em alguns excertos.
} 
EID\&A - Revista Eletrônica de Estudos Integrados em Discurso e Argumentação, Ilhéus, n. 15, jan./jun.2018.

documentos da primeira década deste século, ressoa uma memória recente, em que se trata do refúgio não como "direito humano de gozar de suas liberdades fundamentais", como apregoado pelo Estatuto do Refugiado, que data de 1951, pós Segunda Guerra, mas como forma de proteção dos direitos humanos contra os crimes e a violência do Estado, marcas das ditaduras dos anos 60 a 80, época de formulação da Declaração de Cartagena (1984), por exemplo. Mesmo que essa carta afirme sua "natureza pacífica, apolítica e exclusivamente humanitária", o direito ao asilo de que se tratava na época era concedido aos refugiados políticos. Essa designação é mobilizada nos documentos das IES1 e IES2, nos anos de 2004 e 2008, caracterizando a abertura da Universidade brasileira como voltada, aparentemente, apenas àqueles perseguidos por ideias e ideais. Atribui-se ao refugiado a nobreza de uma causa pela qual se é perseguido e em nome da qual se busca refúgio.

R1)

O CONSELHO DE ENSINO, PESQUISA E EXTENSÃO DA IES2, no uso de suas atribuições estatutárias, considerando: a responsabilidade institucional de prever alguma forma de ingresso de alunos refugiados políticos na IES2; o princípio de autonomia; os incisos IX e XIX do art. 17 do Estatuto da IES2; a Lei no 9474/97, de 20/07/97, que define mecanismos para a implementação do Estatuto dos Refugiados de 1951 e cria o Comitê Nacional para os Refugiados (CONARE); o parecer no 526/96 da Procuradoria Jurídica III, que dispõe sobre o recebimento pela IES2 de transferência de alunos asilados; o Ofício no 3.660/95 da Secretaria de Educação Superior do Ministério da Educação e Desporto (SESu/MEC), que solicita a criação de mecanismos de ingresso dos refugiados políticos nos Cursos de Graduação, resolve:

Art. $1^{\circ}$ Será permitido o ingresso de refugiados políticos na IES2, como alunos dos Cursos de Graduação.

$\S 1^{\circ} \mathrm{A}$ matrícula de refugiados políticos nos referidos cursos condiciona-se à comprovação de que seu pleito de refugiado político foi referendado pelo Comitê Nacional para os Refugiados (CONARE). (IES2, 2004).

$\mathrm{R} 2)$

PORTARIA No $x x x x$, de 09 de junho de 2008

Regulamenta o ingresso de refugiados políticos nos cursos de graduação da IES1 $[\ldots]$

Artigo $1^{\circ}$ - A IES1 viabilizará o ingresso, como alunos, de refugiados políticos nos seus cursos de graduação, em todas as modalidades.

A materialidade linguística dos dois recortes é bastante semelhante, em razão de textualizarem o discurso institucional, que, na perspectiva de Oger e Ollivier-Yaniv (2006, p. 72), caracteriza-se como um discurso oficial que atenua conflitos e polêmicas, por meio de procedimentos discursivos que produzem um efeito de generalização. Dentre esses procedimentos, as autoras destacam 
EID\&A - Revista Eletrônica de Estudos Integrados em Discurso e Argumentação, Ilhéus, n. 15, jan./jun.2018.

"a descontextualização dos enunciados", que "tende a imprimir ao discurso uma temporalidade de longo prazo, para não dizer um caráter universal. Essa temporalidade é característica da instituição e não de seus representantes e membros sucessivos e temporários" ${ }^{\prime 6}$. Essa temporalidade universal ou de longo prazo é sugerida também pela ancoragem (heterogeneidade mostrada no fio do dizer) em outros documentos, leis e no próprio Estatuto do Refugiado (com data indicada), principalmente em R1, que dão amparo à decisão apresentada e contribuem para que esta tenha caráter sólido e inquestionável. Trata-se, já no modo de apresentação do texto, do recurso a argumentos de autoridade, que validam e autorizam o dizer.

No que concerne à designação, tanto em R1 quanto em R2, esta se constitui por meio de um procedimento linguístico de aposição (GUIMARÃES, 2005), visto que se acresce ao nome o adjetivo "político(s)". Essa estrutura apresenta um "funcionamento determinativo", delimitando, precisando sentidos, dando novo corpo a esse nome. São adjunções determinativas dessa ordem que, entretanto, equivocam e desestabilizam os sentidos. Ao incidir e insistir no excerto - refugiado(s) político(s) é retomada cinco vezes em R1 e três vezes em R2 - a formulação deixa entrever, por um lado, que é apenas atendendo a essa condição que o aluno que busca refúgio pode pleitear lugar nas referidas IES. Por outro lado, aponta que é para os refugiados políticos - e não outros - que a acolhida se faz necessária, reverberando, para além da materialidade do dizer, sentidos não ditos.

Essa concepção do "refugiado", na leitura de Jardim (2016), caracterizase como "uma categoria de proteção individual", que apenas posteriormente se alarga. Para a autora, "ela se individualiza enquanto concessão a um pleiteante que deve corresponder a uma série de quesitos que perfazem a seletividade do refugiado entre potenciais refugiados" (JARDIM, 2016, p. 258).

Nos recortes $\mathrm{R}_{3}$ e $\mathrm{R}_{4}$, veiculados em meados da segunda década deste século, o substantivo refugiado(s) e seu determinante, político(s), cedem lugar a "pessoas" e "candidatos". Ambos são, por assim dizer, despolitizados, não pela exclusão do termo, político, evidentemente, mas pela inclinação ao "apagamento dos conflitos" (KRIEG-PLANQUE e OGER, 2010), ao politicamente correto, à amenização ou à "docilização" dos discursos

\footnotetext{
${ }^{6}$ Tradução nossa para: "La décontextualisation des énoncés" [...] Ce procédé tend à imprimer au discours une temporalité sur le long terme, pour ne pas dire un caractère universel. Cette temporalité est bien caractéristique de l'institution et non de ses représentants et membres successifs et temporaires".
} 
EID\&A - Revista Eletrônica de Estudos Integrados em Discurso e Argumentação, llhéus, n. 15, jan./jun.2018.

(SARGENTINI, 2017). Os modos de designar passam a soar mais inclusivos, não restritos a uma única categoria de refugiados. Vejamos:

$\mathrm{R} 3)$

[...] pessoas em situação de refúgio, que sejam portadoras de documentação comprobatória emitida pelo Conare - Comitê Nacional para os Refugiados (IES1, 2014)

R4)

A Pró-Reitoria de Graduação da IES1 faz saber aos interessados, considerando o disposto [...], faz saber aos interessados que estarão abertas as inscrições para processo de seleção simplificada, para preenchimento de uma vaga adicional por curso de graduação presencial da IES1, dentre as que não tiveram candidato selecionado por meio do Edital xxx, destinado a candidatos que comprovem a situação de Refugiado, por meio de atestado emitido pelo Conare - Comitê Nacional para os Refugiados, e que já tenham concluído o nível de Ensino Médio ou equivalente (IES1, 2016)

O procedimento linguístico-discursivo de amenização de possíveis conflitos e, consequentemente, a tentativa de cerceamento dos sentidos, são denominados por Oger e Ollivier-Yaniv (2006) de "lissage", ou seja, alisamento, domesticação, docilização do dizer. Esse procedimento, em R2 e $\mathrm{R} 3$, pode ser compreendido como um movimento de desdobramento ou desopacificação da designação "refugiado", a qual condensa sentidos conflitantes que necessitam, no/pelo discurso institucional, ser explicitados ou apagados.

O “alisamento" silencia elementos e sentidos, transforma e/ou estende a designação, reformulando-a, linguisticamente, por meio da substituição de termos e da inserção de orações restritivas e explicativas. Em um primeiro movimento, passa-se de refugiado ou refugiado político a pessoas em situação de refúgio e candidatos. Em um segundo movimento, presentifica-se, nas subordinadas, o jogo de forças que define quem tem ou não tem acesso ao dispositivo jurídico-administrativo e, consequentemente, à Universidade: que sejam portadoras de documentação comprobatória emitida pelo Conare e que comprovem a situação de Refugiado, por meio de atestado emitido pelo Conare [...] e que já tenham concluído o nível de Ensino Médio.

A reformulação das designações e seus desdobramentos respondem a outros modos de designar o estrangeiro, asilado, migrante, que não é necessariamente refugiado, atestando que o refugiado está em uma posição diferente, garantida por lei. Ele, supostamente, beneficia-se das garantias morais, éticas e jurídicas dessa condição. Ora, essa densa trama de 
EID\&A - Revista Eletrônica de Estudos Integrados em Discurso e Argumentação, llhéus, n. 15, jan./jun.2018.

recategorizações que, argumentativamente, busca definir aqueles elegíveis como refugiados aponta para o fato não só de os sentidos não serem ahistóricos e estarem em constante redefinição, mas também de a designação definir e construir “juridicamente os sujeitos e sua possibilidade de circulação" (JARDIM, 2016, p. 249).

Segundo Jardim, a definição de uma categoria como "refugiado" se insere em uma prática inscrita em dispositivos de governamentalidade, pois

Tais dispositivos se expandem no sentido de dotar de previsibilidade e aprimorar as lógicas da sedentarização manejadas por Estados nacionais, em suas administrações e burocracias, visando à localização e à convergência de debates sobre as nuances entre um nacional e um estrangeiro ou imigrante. Sobretudo, nesse jogo político no âmbito estatal, se explicitam leituras de aspectos morais como parte dos critérios de elegibilidade e singularização de corpos. Identificar, selecionar e categorizar imigrantes é prática constitutiva dos procedimentos administrativos que levam a elegibilidade e admissão de imigrantes e sua distinção de refugiados em novos contextos, de modo individual ou coletivo (JARDIM, 2016, p. 248).

São esses dispositivos jurídicos, como mencionado, que outorgam direito, mas, ao mesmo tempo, argumentam em prol da submissão a tecnologias de classificação e, consequentemente, de distinção e hierarquização entre aqueles que vivenciam o êxodo forçado e aqueles que o vivenciam, mas "com documentação comprobatória”; entre os migrantes e os “migrantes regularmente admitidos no Brasil”, como indica R5, a seguir:

\section{R5)}

A IES4 torna públicas as normas que regem os pedidos de acesso aos cursos de graduação, para o primeiro semestre letivo do ano de 2016, por migrantes regularmente admitidos no Brasil, na condição de refugiados ou portadores de visto humanitário, que tenham iniciado cursos superiores em instituições de ensino no exterior (IES4, 2015).

R6)

[...] DECIDE

aprovar as Normas para Ingresso de pessoas em situação de refúgio em cursos de graduação e pós-graduação stricto sensu da IES5.

[...]

Art. $2^{\circ}$ - Para candidatar-se a cursos de graduação, a pessoa em situação de refúgio deverá cumprir os seguintes requisitos: I - Requerimento de inscrição com indicação do curso pretendido, com base nas vagas disponibilizadas no respectivo edital; II - Comprovação da condição de refugiado reconhecida pelo Comitê Nacional para os Refugiados (CONARE) ou apresentação do protocolo de solicitação de refúgio, de acordo com os procedimentos que regulamentam a Lei 9.474/07; III - Comprovação da escolaridade do Ensino Médio Completo ou seu equivalente (IES5, 2015). 
No âmbito discursivo, para além do aspecto linguístico, as designações presentes em R5 e R6 materializam a problemática da migração não controlada, não regulada pelo Estado, na qual se inserem os migrantes considerados irregulares, infames, enquadráveis, por exemplo, no art. $3^{\circ}$ da Lei $n^{\circ}$ 9.474/1997, como tendo cometido crimes de diversas ordens, de crime contra a humanidade a tráfico de drogas. O movimento das designações no dispositivo jurídico institucional, assim, delimita lugares, imagens e padrões aos quais os estrangeiros, para atender à "condição de refugiado", devem aderir: trata-se de migrantes, mas condicionados à admissão regular no país, e de pessoas em situação de refúgio, mas condicionadas à comprovação de serem ou virem a ser refugiados.

Desse modo, esse movimento intervém na constituição dos sentidos do que é ser refugiado nos termos da lei, retomando definições e nomenclaturas e inscrevendo-se em um dispositivo jurídico historicamente reafirmado, do qual fazem parte, dentre outros, a Declaração de Cartagena (1984), que possui como um dos critérios "adotar a terminologia estabelecida na Convenção e no Protocolo [...] com o objetivo de diferenciar os refugiados de outras categorias de migrantes" e a própria Convenção Relativa ao Estatuto dos Refugiados (1951), que se encarrega da “definição do termo 'refugiado"'. Não se trata, nesses documentos, do direito fundamental de acolhida daqueles que, forçadamente, devem buscar asilo, mas do daqueles que se inserem no enquadramento do dispositivo jurídico, satisfazendo determinadas condições, engendradas como forma de seleção diante de coletividades em fluxo intenso e, por vezes, incontrolável.

Seguindo uma lógica administrativa, ainda de acordo com Jardim (2016, p. 263), "frente à diversidade de motivações desencadeadoras de uma evasão há uma individualização das razões da evasão e da forma de operacionalizar a gestão de coletividades”. Essa categorização, para a autora, “contempla, portanto, uma seletividade que mobiliza a capacidade do sujeito imigrante fazer-se visível pelas organizações que atuam nas localidades como mandatários da proteção internacional”. Esse problema recai, contudo, na produção de zonas de (in)visibilidade nas quais aqueles que buscam asilo podem permanecer. Essas zonas interferem, por exemplo, na possibilidade de ascender a um lugar socialmente reconhecido e/ou de produção de saberes, como a Universidade, relegando o migrante, refugiado ou não, ao espaço de 
EID\&A - Revista Eletrônica de Estudos Integrados em Discurso e Argumentação, llhéus, n. 15, jan./jun.2018.

que compartilham outras minorias nas sociedades contemporâneas: sem voz, sem papéis, sem direitos legalmente reconhecidos e respeitados.

\section{Considerações finais}

O percurso de leitura traçado neste estudo, embora breve, permite compreender que o modo de designar atua não apenas na criação de um referente, mas também na sua categorização e classificação em uma ordem de sujeitos/objetos já dada. A materialidade linguística, nesse sentido, é determinante, por servir de base para o funcionamento discursivo e argumentativo das designações. Estas, por sua vez, inserem-se em uma rede de memória que contribui para sua significação, ao mesmo tempo em que materializa o agenciamento discursivo jurídico-administrativo, ancorado em dispositivos de controle e organização das coletividades.

É na materialidade linguística que se pode observar, por exemplo, o procedimento de "lissage" discursivo, que se encarrega de desdobrar os modos de designar, inserindo-os em dizeres "politicamente corretos" ou “inclusivos". Esse funcionamento, porém, também pode anular a porosidade, as ranhuras e os efeitos contraditórios que uma designação como "refugiado(s)" comporta, tendendo a neutralizar seu caráter fundamentalmente político, ou seja, de divisão dos sentidos e de abertura aos debates/embates. A tendência ao alisamento discursivo, quando desdobradas as designações, também funciona de modo argumentativo, porque se inscreve na relação com o interdiscurso e porque decorre de um deslizamento semântico.

\section{Fontes}

BRASIL. Lei n. 9474, de 22 de jul. de 1997. Define mecanismos para a implementação do Estatuto dos Refugiados de 1951 e determina outras providências. Brasília, DF, jul. 1997. Disponível em: http://www.planalto.gov.br/ccivil_03/leis/L9474.htm. Acesso em: 29 jul. 2016.

ONU. Convenção Relativa ao Estatuto dos Refugiados. Adotada em 28 de julho de 1951 pela Conferência das Nações Unidas de Plenipotenciários sobre o Estatuto dos Refugiados e Apátridas, convocada pela Resolução n. 429 (V) da Assembleia Geral das Nações Unidas, de 14 de dezembro de 1950. Entrou em vigor em 22 de abril de 1954, de acordo com o artigo 43. Série Tratados da ONU, № 2545, Vol. 189, p. 137. 
EID\&A - Revista Eletrônica de Estudos Integrados em Discurso e Argumentação, llhéus, n. 15, jan./jun.2018.

Disponível

em: http://www.acnur.org/t3/fileadmin/Documentos/portugues/BDL/Convencao_relativa_ ao_Estatuto_dos_Refugiados.pdf?view=1. Acesso em: 07 mar. 2018.

ONU. Declaração de Cartagena: conclusões e recomendações. Adotada pelo "Colóquio sobre Proteção Internacional dos Refugiados na América Central, México e Panamá: Problemas Jurídicos e Humanitários", realizado em Cartagena, Colômbia, entre 19 e 22 de Novembro de 1984. Disponível em: http://www.acnur.org/t3/fileadmin/Documentos/portugues/BD_Legal/Instrumentos_1 nternacionais/Declaracao_de_Cartagena.pdf?view=1. Acesso em: 07 mar. 2018.

\section{Referências}

AMOSSY, Ruth. Argumentação e análise do discurso: perspectivas teóricas e recortes disciplinares. Trad. Eduardo L. Piris e Moisés O. Ferreira. EID\&A - Revista Eletrônica de Estudos Integrados em Discurso e Argumentação, Ilhéus, n. 1, p. 129-144, nov. 2011.

FOUCAULT, Michel. A arqueologia do saber. Trad. Luiz Felipe Baeta Neves. $7^{\mathrm{a}}$. Ed. Rio de Janeiro: Forense Universitária, 2009.

GUIMARÃES, Eduardo. Designação e espaço de enunciação: um encontro político no cotidiano. Revista Letras, n. 26. Santa Maria: PPGL/UFSM, 2003, p. 53-62.

JARDIM, Denise. Imigrantes ou refugiados? As tecnologias de governamentalidade e o êxodo palestino rumo ao brasil no século XX. Horizontes Antropológicos, Porto Alegre, ano 22, n. 46, p. 243-271, jul./dez. 2016.

KRIEG-PLANQUE, Alice; OGER, Claire. (2010). Discours institutionnels. Perspectives pour les sciences de la communication. Mots. Les langages du politique, n. 94, nov. 2010, p. 91-96.

NUNES, José Horta. Lexicologia e lexicografia. In: GUIMARÃES, Eduardo; ZOPPIFONTANA, Mónica (Org.). A palavra e a frase. Campinas: Pontes, 2006, p. 147-165.

OGER, Claire; OLLIVIER-YANIV, Caroline. Conjurer le désordre discursif. Les procédés de " lissage » dans la fabrication du discours institutionnel, Mots. Les langages du politique, 81, p. 63-77, 2006. Disponível em: http://journals.openedition.org/mots/675. Acesso em: 07 mar. 2018.

ORLANDI, Eni. Discurso e Argumentação: um observatório do político. Forum Linguístico. Florianópolis, n. 1, jul.-dez. 1998, p. 71-81.

PÊCHEUX, Michel. O discurso: estrutura ou acontecimento. Trad. Eni Orlandi. Campinas: Pontes, 1990. 
EID\&A - Revista Eletrônica de Estudos Integrados em Discurso e Argumentação, llhéus, n. 15, jan./jun.2018.

RANCIÈRE, Jacques. Aux bords du politique. Paris: Gallimard, 1998.

RANCIÈRE, Jacques. Le partage du sensible. Paris: La Fabrique, 2000.

SARGENTINI, Vanice Maria. Mutações do discurso político: segmentação, docilização e estetização. In: SARGENTINI, Vanice Maria (Org.). Mutações do discurso político no Brasil: espetáculo, poder e tecnologias de comunicação. Campinas: Mercado de Letras, 2017, p. 85-106.

VOIROL, Olivier. Les luttes pour la visibilité. Esquisse d'une problématique. Réseaux, n. 129-130, p. 89-121, 2005.

Forma de citação sugerida:

Da ROSA, Marluza. O funcionamento argumentativo em torno da designação "refugiados" no discurso universitário brasileiro. EID\&A - Revista Eletrônica de Estudos Integrados em Discurso e Argumentação, Ilhéus, n. 15, p. 162-174, jan./jun.2018. 